\title{
Surgical Treatment in Papillary Thyroid Microcarcinom
}

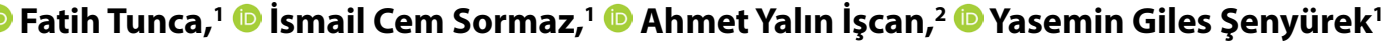

'Department of General Surgery, İstanbul University Faculty of Medicine, İstanbul, Turkey

${ }^{2}$ Department of General Surgery, Fatih Sultan Mehmet Training and Research Hospital, İstanbul, Turkey

\begin{abstract}
Despite the notable increasing incidence of papillary thyroid microcarcinoma (PTMC), the optimal treatment of the patients with PTMC remains controversial. Because of no consensus about its treatment, the suggested treatment varies from active surveillance alone to total thyroidectomy. Although the 2015 revised American Thyroid Association guideline recommends hemithyroidectomy as the first-line treatment, active surveillance has also been discussed and accepted as another approach for the patients with PTMC. However, the same guideline does not recommend fine needle aspiration biopsy for nodules sized $<1 \mathrm{~cm}$, even it is suspicious. In such situation, neither active surveillance nor hemithyroidectomy could be discussed, with a lack of objective cytologic data about the nodules sized $<1 \mathrm{~cm}$. In this situation, the decision to perform FNAB to the nodules $<1 \mathrm{~cm}$ in size depends on the performer of the thyroid ultrasonography.

In this invited review, we have discussed the diagnosis and prognostic factors for PTMCs. We have also discussed surgical strategies as the accepted the first-line treatment in patients with PTMC.

Keywords: Papillary thyroid microcarcinoma; surgery.

Please cite this article as "Tunca F, Sormaz IC, İşcan AY, Giles Şenyürek Y. Surgical Treatment in Papillary Thyroid Microcarcinom. Med Bull Sisli Etfal Hosp 2018;52(4):244-248".
\end{abstract}

In the last three decades, thyroid cancer is the fastest growing malignancy. ${ }^{[1]}$ Approximately 65.000 new cases are diagnosed each year in United States. The incidence of papillary thyroid cancer (PTC) tripled, largely due to an increase in the incidence of papillary thyroid microcarcinoma (PTMC) ${ }^{[2]}$ According to the Turkey's Ministry of Health 2013 statistics, thyroid cancer is the second most common cancer (most common is the breast cancer) in young female population (ages between 25 and 54).

The World Health Organization defines PTMC as papillary carcinoma with a diameter of $<1 \mathrm{~cm} \cdot{ }^{[3]}$ Because of lack of consensus regarding the natural history of PTMC, suggested treatment of PTMC ranges from observation alone to total thyroidectomy (TT) with radioactive iodine (RAI) ablation. Recent changes in the American Thyroid Association (ATA) guidelines now recommend lobectomy as the first-line treatment for patients with PTMC except patients with features that would indicate TT, such as nodal metastasis or a family history of thyroid cancer. ${ }^{[4]}$ The revised ATA guidelines (2015) added a less aggressive approach, active surveillance (AS) with serial ultrasounds, as an alternative management strategy. ${ }^{[4]}$ However, the recent ATA guideline also recommends not to perform fine needle aspiration biopsy (FNAB) even in suspicious nodules sized $<1 \mathrm{~cm}$. But how can PMTC be diagnosed if we do not perform FNAB in these nodules? In such situation, neither AS nor surgery can be discussed without any objective data demonstrating that the patient had a PMTC.

Address for correspondence: Fatih Tunca, MD. İstanbul Üniversitesi Tıp Fakültesi, Genel Cerrahi Anabilim Dalı, İstanbul, Turkey Phone: +90 5322231280 E-mail: drfatihtunca@yahoo.com

Submitted Date: December 18, 2018 Accepted Date: December 18, 2018 Available Online Date: December 28, 2018

${ }^{\circ}$ Copyright 2018 by The Medical Bulletin of Sisli Etfal Hospital - Available online at www.sislietfaltip.org

This is an open access article under the CC BY-NC-ND license (http://creativecommons.org/licenses/by-nc/4.0/). 
Advocates of AS hypothesized that most PTMCs would remain small and would not develop into clinically significant disease. Miyauchi et al. ${ }^{[5]}$ posited that the few PMCs that show slight disease progression would be effectively treated when they progress, and that immediate surgery for all PMCs would result in more harm than good. The AS trial for low-risk PMC began at the Kuma Hospital in 1993. A similar trial started at the Cancer Institute Hospital in Tokyo in 1995. ${ }^{[6]}$ These Japanese studies as well as the studies from the United States and Korea showed safety of the AS management. None of the patients died of thyroid cancer or developed distant metastasis, although a small minority of the patients who showed slight disease progression underwent surgical treatment. ${ }^{[6]}$ On the other hand, the $1 \%-2.8 \%$ of patients with PTMC with distant metastases at diagnosis had a worse prognosis, with high rates of persistence/ recurrence. ${ }^{[7]}$ However, Kwon et al ${ }^{[8]}$ reported extrathyroid and thus advanced tumor growth in 34\% of the PTMC operated on the basis of size progression or on request of the patients who were initially only observed.

Furthermore, the ATA guidelines acknowledge the importance of patient preference in the decision-making process, and they emphasize the need to "minimize treatment-related morbidity and unnecessary therapy".[4, 9] Potential treatment-related morbidities in patients with PTMC can impair quality of life. ${ }^{[10-12]}$ However, hemithyroidectomy is still the first-line treatment method for PTMC in most of the endocrine surgery centers worldwide.

\section{Diagnosis of PMTC}

PTMCs are usually asymptomatic, and they are rarely detected by physical examinations. Most of the PMTCs are detected incidentally by neck ultrasonography. Because of its noninvasive nature and improved technology, ultrasonography is used as the first option in all the imaging studies to screen thyroid diseases and detect small thyroid nodules measuring $3.0 \mathrm{~mm}$ or larger. In addition to the size of the nodule, ultrasonography should also contain information about inhomogeneities of the parenchyma, an edge blurring, hypervascularization, and microcalcifications. In addition to these already established criteria, Miyauchi recommends an exact description of the carcinoma in relation to the thyroid capsule and the trachea. US should also give information about the central and lateral cervical lymph nodes. ${ }^{[13]}$ In practice, an ultrasound assessment of the central lymph nodes due to their localization dorsal and caudal to the thyroid gland is limited. However, lateral cervical lymph nodes, on the other hand, are easier to visualize.

Because of its high diagnostic reliability, the US-guided FNAB has been widely accepted as initial diagnostic test for the suspicious thyroid nodules. The cytological examination of a FNA requires experienced cytologist, and yet cannot reliably detect some subgroups such as follicular variant. The detection of a BRAF (V600E) mutation can demonstrably improve the cytological diagnosis of PTC. ${ }^{[14]}$ In a meta-analysis, BRAF (V600E)-positive tumors showed strikingly frequent multifocal carcinomas, extrathyroid tumor growth, and lymph node metastases in the final histopathological evaluation. ${ }^{[15]}$ However, according to the recent ATA guideline, FNAB is not indicated for nodules sized $<1 \mathrm{~cm}^{\left[{ }^{[4]}\right.}$ In this situation, the decision to perform FNAB depends on the performer of the thyroid US.

\section{Prognosis}

The overall survival for PTMC in a meta-analysis including more than 18.000 PTMC cases for the 10-year and 15-year overall survival was reported to be $95 \%$ and $91 \%$, respectively. In addition, the 10-year disease-specific survival is approximately $99.5 \%$, which suggests that $0.5 \%$ patients may die of PTMC. ${ }^{[16]}$ However, PTMC is not a homogeneous entity, and better prognosis stratification, especially for high-risk patients, optimizes surgical care.

Age is a prognostic factor for patients with differentiated thyroid cancer. A recent report from the SEER data program showed that the death rate from thyroid cancer is $2.7 / 100.000$ in patients aged more than 65 years, whereas it is only $0.1 / 100.000$ in patients aged less than 65 years. ${ }^{[17-20]}$ In a recent population-based study, age was found as the most powerful prognostic factor among all the analyzed factors. Male patients had less-favorable prognosis than the female patients $(p<0.001)$ had. The 15 -year survival rate for the male patients was about $86 \%$, while the survival reached $92 \%$ for the female patients. ${ }^{[16]}$

Size remains controversial whether it serves as a prognostic factor for PTMC. Microcarcinomas with 5-10 mm diameter foci and $5 \mathrm{~mm}$ diameter or less have different incidences of lymph node metastasis ( $59 \%$ vs $13 \%$, respectively) and extrathyroidal invasion ( $10 \%$ vs $3 \%$, respectively). ${ }^{[21]}$ Although tumor size larger than $5 \mathrm{~mm}$ was found to be associated with recurrent PTMC in a univariate model, it was not significantly related either with disease-free survival or with overall survival in the multivariate analysis. ${ }^{[16,22,23]}$

Extrathyroidal invasion (ETE) is another important risk factor that all of the staging algorithms. The ETE rate for PTMC varies from $2 \%$ to $21 \%{ }^{[24,25]}$ in different studies. This variation may be caused by different locations of the PTMC. PTMCs close to the thyroid capsule are more likely to show ETE. The TNM system defines T4 disease as tumor of any size extending beyond thyroid capsule, which means that a PTMC can be T4 disease. The presence of distant metas- 
tases had a strong predictive value for unfavorable survival $(\mathrm{HR}=3.76 ; 95 \% \mathrm{Cl}, 1.22-11.62 ; \mathrm{p}=0.021)$. Lymph node metastases $(H R=1.36 ; p=0.011)$ were also associated with an adverse prognosis in the patients with PTMC. ${ }^{[16]}$

Multifocality is not considered as a prognostic factor in any of the current staging systems. However, multifocality is associated with a higher rate of tumor recurrence. A study shows that only $1.2 \%$ of patients with unifocal disease had recurrent cancer, whereas the recurrence rate reached $8.6 \%$ in patients with multifocal disease. ${ }^{[26]}$ Similar observations were reported by another study revealing a 5.6 fold increased risk for cervical lymph node recurrence when multifocal disease was present at diagnosis. ${ }^{[27]}$

\section{Surgical Strategy}

The ATA, ${ }^{[4]}$ British Thyroid Association, ${ }^{[27]}$ and the German Society of General and Visceral Surgery ${ }^{[29]}$ recommend using hemithyroidectomy as the first-line treatment in patients with PTMC. However, TT is indicated in familial papillary thyroid carcinoma (FNMTC), which is detected in $5 \%$ of patients with PTC, ${ }^{[4,27,29]}$ as these carcinomas become more multifocal and metastasize early. ${ }^{[30,31]}$ Radiation therapy of neck in the medical history is another TT indication. Detecting multifocal carcinomas preoperatively is also an indication for TT in patients with PTMC. ${ }^{[4]}$

In a meta-analysis including more than 18.000 PTMCs, the impact of risk factors on PTMC's outcome was further analyzed. There were 5033 patients with two or more risk factors in the study, and the overall survival rate for these patients was significantly worse than those with less than two risk factors (15-year survival rate, $83.0 \%$ vs $93.4 \%$; $\mathrm{p}<0.0001)$. The result of 1042 patients with three or more risk factors was more unfavorable compared with that of patients without any risk factors (15-year survival rate, $75.8 \%$ vs $91.5 \% ; p<0.0001)$. In this study, the surgery type and the prognosis was also evaluated, and the authors found that PTMCs with two or more risk factors had better prognosis if TT was performed $(\mathrm{HR}=0.70 ; 95 \% \mathrm{Cl}, 0.51-0.96$; $\mathrm{p}=0.026$ ) compared with if either hemithyroidectomy or near-TT was performed. In addition, TT benefited the patients with three or more risk factors $(\mathrm{HR}=0.49 ; 95 \% \mathrm{Cl}$, $0.25-0.97 ; p=0.042){ }^{[16]}$

Kim et al. ${ }^{[32]}$ investigated 8676 patients (5387 thyroidectomies, 3289 hemithyroidectomies) with a PTMC. The average follow-up period was 65 months. The recurrence-free 5-year and 10-year survival rates were $98.1 \%$ and $91.8 \%$, respectively, for the hemithyroidectomy group; and $98.5 \%$ and $97.5 \%$ for the TT group ( $p<0.001)$. The majority of the diagnosed "tumor recurrences" involved the contralateral thyroid lobes left in hemithyroidectomy. In multifocal car- cinomas, TT significantly reduced the risk of actual local recurrence. Therefore, the authors concluded that lobectomy did not increase the risk of loco-regional recurrence outside the contralateral remnant lobe in patients with PTMC, except patients with multifocality. The recurrence in the contralateral remnant lobe can be safely managed by completion thyroidectomy, so lobectomy may be a safe operative option for select patients with PTMC without multifocality.

In 2016, Gschwandtner et al. published comparable results with 1.2\% PTMC "recurrences" in the contralateral thyroid lobe after hemithyroidectomy. Central lymph node recurrences after thyroidectomy were found in only $0.4 \%$ of the patients. In this study, the authors found that nodal recurrence was significantly associated with nodal metastases at primary surgery. ${ }^{[33]}$ Nonincidental PTMC had an increased risk of developing recurrence in lymph nodes. It was found that young patients were more likely to develop lymph node recurrences. Aggregate tumor size and subcapsular localization were also found significantly associated with lymph node recurrences. The authors concluded that micrometastases are seemingly not clinically relevant. Most PTMCs, even if they are multifocal, can be sufficiently treated without a completion thyroidectomy and without postoperative radioiodine treatment, but if lymph node metastases are suspected preoperatively or intraoperatively and are histologically confirmed, a radical surgical concept, including a TT and an adequate lymphadenectomy, should be performed. ${ }^{[33]}$

The indication for central and lateral cervical lymph node dissection in the PTMC exists only in the case of preoperative or intraoperative suspicion or proof of lymph node metastasis and not prophylactically. ${ }^{[4,29]}$

\section{Conclusion}

Hemithyroidectomy, according to the guidelines of most surgical societies, is still the therapy of choice for PTMC. It gives excellent results with very low complication rates. The cure of PTMC is possible only through surgery. AS is an alternative approach, and it should only be performed under well-defined and controlled conditions. TT is indicated only in the presence of multifocal carcinomas, extrathyroid tumor growth, hereditary tumors (FNMTC), and children and adolescents. Systematic lymphadenectomy is reserved for cases with imaging (sonography/magnetic resonance imaging) or intraoperatively detected lymph node metastases. Regardless of known surgical therapy or new concepts such as "active surveillance," it is important to plan the best possible and successful treatment for each patient, taking into account their individual circumstances. 


\section{Disclosures}

Peer-review: Externally peer-reviewed.

Conflict of Interest: None declared.

\section{References}

1. A Snapshot of Thyroid Cancer: Incidence and mortality.National Cancer Institute, Bethesda, MD, 2014. Available at: https://www. cancer.gov/research/progress/snapshots/thyroid.

2. Davies L, Welch HG. Current thyroid cancer trends in the United States. JAMA Otolaryngol Head Neck Surg 2014;140:317-22.

3. Hedinger CE, Williams ED, World Health Organization. Histological typing of thyroid tumours. 2nd ed. Berlin: Springer; 1993. p. 66.

4. Haugen BR, Alexander EK, Bible KC, Doherty GM, Mandel SJ, Nikiforov YE, et al. 2015 American Thyroid Association Management Guidelines for Adult Patients with Thyroid Nodules and Differentiated Thyroid Cancer: The American Thyroid Association Guidelines Task Force on Thyroid Nodules and Differentiated Thyroid Cancer. Thyroid 2016;26:1-133. [CrossRef]

5. Miyauchi A, Ito Y, Oda H. Insights into the Management of Papillary Microcarcinoma of the Thyroid. Thyroid 2018;28:23-31. [CrossRef]

6. Ito Y, Miyauchi A, Oda H. Low-risk papillary microcarcinoma of the thyroid: A review of active surveillance trials. Eur J Surg Oncol 2018;44:307-315. [CrossRef]

7. Yu XM, Lloyd R, Chen $\mathrm{H}$. Current treatment of papillary thyroid microcarcinoma. Adv Surg 2012;46:191-203. [CrossRef]

8. Kwon H, Oh HS, Kim M, Park S, Jeon MJ, Kim WG, et al. Active Surveillance for Patients With Papillary Thyroid Microcarcinoma: A Single Center's Experience in Korea. J Clin Endocrinol Metab 2017;102:1917-25. [CrossRef]

9. Adam MA, Pura J, Gu L, Dinan MA, Tyler DS, Reed SD, et al. Extent of surgery for papillary thyroid cancer is not associated with survival: an analysis of 61,775 patients. Ann Surg 2014;260:601-5. [CrossRef]

10. Wang TS, Goffredo P, Sosa JA, Roman SA. Papillary thyroid microcarcinoma: an over-treated malignancy? World J Surg 2014;38:2297-303. [CrossRef]

11. Hauch A, Al-Qurayshi Z, Randolph G, Kandil E. Total thyroidectomy is associated with increased risk of complications for low- and high-volume surgeons. Ann Surg Oncol 2014;21:3844-52. [CrossRef]

12. Rosato L, Pacini F, Panier Suffat L, Mondini G, Ginardi A, Maggio $M$, et al. Post-thyroidectomy chronic asthenia: self-deception or disease? Endocrine 2015;48:615-20. [CrossRef]

13. Miyauchi A. Clinical Trials of Active Surveillance of Papillary Microcarcinoma of the Thyroid. World J Surg 2016;40:516-22. [CrossRef]

14. MusholtTJ, Fottner C, Weber MM, Eichhorn W, Pohlenz J, Musholt $\mathrm{PB}$, et al. Detection of papillary thyroid carcinoma by analysis of BRAF and RET/PTC1 mutations in fine-needle aspiration biopsies of thyroid nodules. World J Surg 2010;34:2595-603. [CrossRef]

15. Li F, Chen G, Sheng C, Gusdon AM, Huang Y, Lv Z, et al. BRAFV600E mutation in papillary thyroid microcarcinoma: a meta-analysis. Endocr Relat Cancer 2015;22:159-68. [CrossRef]
16. Yu XM, Wan Y, Sippel RS, Chen H. Should all papillary thyroid microcarcinomas be aggressively treated? An analysis of 18,445 cases. Ann Surg 2011;254:653-60. [CrossRef]

17. Hay ID, Grant CS, Taylor WF, McConahey WM. Ipsilateral lobectomy versus bilateral lobar resection in papillary thyroid carcinoma: a retrospective analysis of surgical outcome using a novel prognostic scoring system. Surgery 1987;102:1088-95.

18. Hay ID, Bergstralh EJ, Goellner JR, Ebersold JR, Grant CS. Predicting outcome in papillary thyroid carcinoma: development of a reliable prognostic scoring system in a cohort of 1779 patients surgically treated at one institution during 1940 through 1989. Surgery 1993;114:1050-7.

19. Cady B, Rossi R. An expanded view of risk-group definition in differentiated thyroid carcinoma. Surgery 1988;104:947-53.

20. Greene FL, Page DL, Fleming ID, Fritz AG, Balch CM, Haller DG, editors. AJCC cancer staging manual. 6th ed. New York: Springer-Verlag; 2002. [CrossRef]

21. Kasai N, Sakamoto A. New subgrouping of small thyroid carcinomas. Cancer 1987;60:1767-70. [CrossRef]

22. Giordano D, Gradoni P, Oretti G, Molina E, Ferri T. Treatment and prognostic factors of papillary thyroid microcarcinoma. Clin Otolaryngol 2010;35:118-24. [CrossRef]

23. Pellegriti G, Scollo C, Lumera G, Regalbuto C, Vigneri R, Belfiore A. Clinical behavior and outcome of papillary thyroid cancers smaller than $1.5 \mathrm{~cm}$ in diameter: study of 299 cases. J Clin Endocrinol Metab 2004;89:3713-20. [CrossRef]

24. Bernet V. Approach to the patient with incidental papillary microcarcinoma. J Clin Endocrinol Metab 2010;95:3586-92. [CrossRef]

25. Hay ID, Hutchinson ME, Gonzalez-Losada T, Mclver B, Reinalda ME, Grant CS, et al. Papillary thyroid microcarcinoma: a study of 900 cases observed in a 60-year period. Surgery 2008;144:9807. [CrossRef]

26. Baudin E, Travagli JP, Ropers J, Mancusi F, Bruno-Bossio G, Caillou $B$, et al. Microcarcinoma of the thyroid gland: the GustaveRoussy Institute experience. Cancer 1998;83:553-9. [CrossRef]

27. Chow SM, Law SC, Chan JK, Au SK, Yau S, Lau WH. Papillary microcarcinoma of the thyroid-Prognostic significance of lymph node metastasis and multifocality. Cancer 2003;98:31-40. [CrossRef]

28. Perros P, Boelaert K, Colley S, Evans C, Evans RM, Gerrard Ba G, et al. Guidelines for the management of thyroid cancer. Clin Endocrinol (Oxf) 2014;81 Suppl 1:1-122. [CrossRef]

29. AWMF. Operative Operative Therapie maligner Schilddrüsenerkrankungen. 2012. Available at: https://www.aco-asso.at/wp/ wp-content/uploads/2014/01/Leitlinien-SDCA.pdf. Accessed Dec 26, 2018.

30. Hillenbrand A, Varhaug JE, Brauckhoff M, Pandev R, Haufe S, Dotzenrath $C$, et al. Familial nonmedullary thyroid carcinomaclinical relevance and prognosis. A European multicenter study. ESES Vienna presentation. Langenbecks Arch Surg 2010;395:8518. [CrossRef]

31. Lee CR, Park S, Kang SW, Lee J, Jeong JJ, Nam KH, et al. Is familial 
papillary thyroid microcarcinoma more aggressive than sporadic form? Ann Surg Treat Res 2017;92:129-35. [CrossRef]

32. Kim SK, Park I, Woo JW, Lee JH, Choe JH, Kim JH, et al. Total thyroidectomy versus lobectomy in conventional papillary thyroid microcarcinoma: Analysis of 8,676 patients at a single institu- tion. Surgery 2017;161:485-92. [CrossRef]

33. Gschwandtner E, Klatte T, Swietek N, Bures C, Kober F, Ott J, et al. Increase of papillary thyroid microcarcinoma and a plea for restrictive treatment: A retrospective study of 1,391 prospective documented patients. Surgery 2016;159:503-11. [CrossRef] 